\title{
Post-polypectomy colonoscopy surveillance: European Society of Gastrointestinal Endoscopy (ESGE) Guideline
}

Authors

Institutions
Cesare Hassan ${ }^{1}$, Enrique Quintero ${ }^{2,3}$, Jean-Marc Dumonceau ${ }^{4}$, Jaroslaw Regula ${ }^{5}$, Catarina Brandão ${ }^{6}$, Stanislas Chaussade $^{7}$, Evelien Dekker ${ }^{8}$, Mario Dinis-Ribeiro ${ }^{6}$, Monika Ferlitsch ${ }^{9}$, Antonio Gimeno-García ${ }^{2,3}$, Yark Hazewinkel $^{8}$, Rodrigo Jover $^{3,10}$, Mette Kalager ${ }^{11,12}$, Magnus Loberg ${ }^{12,13}$, Christian Pox ${ }^{14}$, Bjorn Rembacken ${ }^{15}$, David Lieberman ${ }^{16}$

Institutions are listed at the end of article. submitted

1. January 1001

accepted after revision

1. January 1001

\section{Bibliography}

DOI http://dx.doi.org/

10.1055/s-0033-1344548

Published online: 12.9.2013

Endoscopy 2013; 45: 842-851

(c) Georg Thieme Verlag KG

Stuttgart · New York

ISSN 0013-726X

\section{Corresponding author}

Cesare Hassan, MD

Digestive Endoscopy Unit

Catholic University

Largo F. Vito 1

00168 Rome

Italy

Fax: +39-6-30156581

cesareh@hotmail.com

This Guideline is an official statement of the European Society of Gastrointestinal Endoscopy (ESGE). The Grading of Recommendations Assessment, Development, and Evaluation (GRADE) system was adopted to define the strength of recommendations and the quality of evidence.

Main recommendations: The following recommendations for post-polypectomy endoscopic surveillance should be applied only after a high quality baseline colonoscopy with complete removal of all detected neoplastic lesions.

1 In the low risk group (patients with $1-2$ tubular adenomas $<10 \mathrm{~mm}$ with low grade dysplasia), the ESGE recommends participation in existing national screening programmes 10 years after the index colonoscopy. If no screening programme is available, repetition of colonoscopy 10 years after the index colonoscopy is recommended (strong recommendation, moderate quality evidence).

2 In the high risk group (patients with adenomas with villous histology or high grade dysplasia or $\geq 10 \mathrm{~mm}$ in size, or $\geq 3$ adenomas), the ESGE recommends surveillance colonoscopy 3 years after the index colonoscopy (strong recommendation, moderate quality evidence). Patients with 10 or more adenomas should be referred for genetic counselling (strong recommendation, moderate quality evidence).

Abbreviations
$\begin{array}{ll}\text { CRC } & \text { colorectal cancer } \\ \text { ESGE } & \begin{array}{l}\text { European Society of Gastrointestinal } \\ \text { Endoscopy }\end{array} \\ \text { g-FOBT/FIT } & \text { guaiac-based faecal occult blood test/ } \\ & \text { faecal immunochemical test } \\ \text { HGD } & \text { high grade dysplasia }\end{array}$

3 In the high risk group, if no high risk adenomas are detected at the first surveillance examination, the ESGE suggests a 5-year interval before a second surveillance colonoscopy (weak recommendation, low quality evidence). If high risk adenomas are detected at first or subsequent surveillance examinations, a 3-year repetition of surveillance colonoscopy is recommended (strong recommendation, low quality evidence).

4 The ESGE recommends that patients with serrated polyps $<10 \mathrm{~mm}$ in size with no dysplasia should be classified as low risk (weak recommendation, low quality evidence). The ESGE suggests that patients with large serrated polyps $(\geq 10 \mathrm{~mm})$ or those with dysplasia should be classified as high risk (weak recommendation, low quality evidence).

5 The ESGE recommends that the endoscopist is responsible for providing a written recommendation for the post-polypectomy surveillance schedule (strong recommendation, low quality evidence).

\section{Introduction \\ $\nabla$}

Colorectal cancer (CRC) represents a major cause of morbidity and mortality in Western countries [1 - 3]. CRC screening has been shown to be effective in reducing CRC incidence and/or mortality [4-7], and population-based screening is widely recommended in Europe [8]. The effect of endoscopic screening is conveyed via two mechanisms. First, removal of precancerous adenomatous polyps at the time of the index examination and the detection of CRC at an early stage reduce CRC incidence and/or mortality [4,9-11]. Secondly, stratification based on the endoscopic 
findings allows patients at greater risk to benefit from endoscopic surveillance [12-14]. Patients with adenomatous polyps are at greater risk of future development of advanced neoplasia (adenomas $\geq 10 \mathrm{~mm}$ or with unfavourable histology or cancer) [15-18]. This may be because serious lesions were missed or not radically removed at the initial examination, or because an inherent imbalance of cell proliferation in an individual leads to accelerated carcinogenesis in apparently normal mucosa $[16,19-23]$.

It is assumed that if patients in whom precancerous polyps have been found are entered into a surveillance programme, then metachronous or recurrent adenomatous lesions and cancer will be detected at an earlier stage. However, no randomized study has directly assessed how much benefit is contributed by the efficacy of post-polypectomy surveillance. The efficacy of endoscopic surveillance has been addressed only in epidemiological series. Such studies have indicated that patients who are not entered into a surveillance programme have a three- to fourfold greater risk of CRC $[18,23]$.

Screening series have reported an adenoma prevalence of $15 \%$ $30 \%[12,13,24,25]$. With the use of high definition colonoscopy equipment, adenomas are found in up to $50 \%$ of the population $[26,27]$. Thus, an indiscriminate use of post-polypectomy surveillance would represent a substantial burden on endoscopy resources, also resulting in unnecessary costs and longer waiting times for other indications. Currently, close to $20 \%$ of endoscopic capacity is occupied by surveillance colonoscopies, approximately the same proportion as primary screening examinations [28-30]. With several European countries initiating population-based screening programmes, the burden of surveillance can be expected to increase in the near future. Although colonoscopy is generally regarded as a safe procedure, a risk of major complications remains [31]. In patients at increased risk of developing cancer, the balance of benefit and risk is generally regarded as favourable. However, the risks, albeit small, may become relevant if the gain associated with surveillance colonoscopies is substantially reduced.

When considering the lack of strong evidence to support postpolypectomy surveillance, and the substantial workload involved, a conservative approach would appear reasonable. It should be remembered that the aim of population-based CRC screening is to reduce the incidence and mortality of CRC, and to do so with a sustainable expenditure of medical and economic resources. For the best balance between the benefits and drawbacks of post-polypectomy surveillance, it should only be offered to patients with a substantial residual risk of CRC. Epidemiological and clinical studies have shown that it is possible to stratify the risk of CRC and to identify a small subgroup of patients with a greater incidence of CRC that persists after baseline polypectomy $[21,32]$.

The aim of this evidence-based and consensus-based Guideline, commissioned by the European Society of Gastrointestinal Endoscopy (ESGE), is to provide caregivers with a comprehensive review of risk stratification following removal of precancerous neoplastic lesions and with practical recommendations for scheduling endoscopic surveillance. This Guideline does not address surveillance after endoscopic or surgical resection of a malignant polyp, or surveillance in patients affected by hereditary colorectal syndromes.

\section{Methods}

\section{$\nabla$}

The ESGE commissioned this Guideline. The guideline development process included meetings, telephone conferences, and online discussions among members of the guideline committee during February 2012 and February 2013.Subgroups were formed, each in charge of a series of clearly defined key questions ( $\bullet$ Appendixe1, available online). The committee chairs (C.H., J.M.D.) worked with the subgroup leaders (J.M.D., E.Q., J.R.) to identify pertinent search terms that always included, as a minimum, "post-polypectomy endoscopic surveillance" as well as terms pertinent to specific key questions. Searches were performed in Medline. Articles were first selected by title; their relevance was then confirmed by review of the corresponding manuscripts, and articles with content that was considered irrelevant, including that relating to hereditary colorectal syndromes, were excluded. A repository of selected literature was made available to all members of the guideline development group. Evidence tables were generated for each key question, summarizing the evidence of the available studies. For important outcomes, articles were individually assessed by means of the Grades of Recommendation Assessment, Development, and Evaluation (GRADE) system for grading evidence levels and recommendation strengths ( $\bullet$ Appendixe2, available online) [33].

Each subgroup developed draft proposals that were presented to the entire group for general discussion during a meeting held in February 2013 (Düsseldorf, Germany). Further details on the methodology of ESGE guidelines have been reported elsewhere [33].

In March 2013, a draft prepared by C.H. was sent to all group members. After agreement on a final version, the manuscript was submitted to Endoscopy for publication. The journal subjected the manuscript to peer review, and the manuscript was amended to take into account the reviewers' comments. All authors agreed on the final revised manuscript.

This Guideline was issued in 2013 and will be considered for review in 2018 , or sooner if new and relevant evidence becomes available. Any updates to the guideline in the interim will be no-

Box 1 Main definitions adopted for this Guideline.

\begin{tabular}{|l|l|}
\hline Term & Definition \\
\hline $\begin{array}{l}\text { High quality } \\
\text { colonoscopy }\end{array}$ & $\begin{array}{l}\text { Complete colonoscopy with a meticulous } \\
\text { inspection of adequately cleaned colorectal } \\
\text { mucosa. Neoplastic lesions have also been com- } \\
\text { pletely removed and retrieved for histological } \\
\text { examination. }\end{array}$ \\
\hline Index colonoscopy & $\begin{array}{l}\text { First high quality colonoscopy on which surveil- } \\
\text { lance strategy is based }\end{array}$ \\
\hline Metachronous lesion & $\begin{array}{l}\text { Any lesion that is detected at surveillance colo- } \\
\text { noscopies }\end{array}$ \\
\hline Low risk group & $\begin{array}{l}1-2 \text { tubular adenomas }<10 \text { mm with low-grade } \\
\text { dysplasia; serrated polyps }<10 \text { mm and no dys- } \\
\text { plasia }\end{array}$ \\
\hline High risk group & $\begin{array}{l}\text { Adenoma with villous histology or high grade } \\
\text { dysplasia or } \geq 10 \text { mm in size, or } \geq 3 \text { adenomas; } \\
\text { serrated polyps } \geq 10 \text { mm or with dysplasia }\end{array}$ \\
\hline Advanced adenoma & $\begin{array}{l}\text { Adenoma with villous histology or high grade } \\
\text { dysplasia or } \geq 10 \text { mm in size }\end{array}$ \\
\hline Advanced neoplasia & $\begin{array}{l}\text { Adenoma with villous histology or high grade } \\
\text { dysplasia or } \geq 10 \text { mm in size, or colorectal cancer } \\
\text { Hyperplastic polyps, sessile serrated polyp, tra- } \\
\text { ditional serrated adenomas, and mixed lesions }\end{array}$ \\
\hline Serrated polyp &
\end{tabular}


ted on the ESGE website: http://www.esge.com/esge-guidelines. html.

\section{Recommendations and statements}

$\nabla$

Evidence statements and recommendations are stated in italics, key evidence statements and recommendations are in bold. See - Box 1 for main definitions for this Guideline.

The following recommendations for post-polypectomy endoscopic surveillance should only be applied after $a$ high quality baseline colonoscopy with complete removal of all detected neoplastic lesions.

Colonoscopy that is performed in quality-controlled settings has been associated with a substantial reduction in subsequent CRC incidence and mortality and with a very low risk of metachronous advanced neoplasia $[4,34,35]$. However, large observational studies have recently shown that the protective effect of colonoscopy, whether or not it includes polypectomy, is reduced when it is done in suboptimal conditions $[5,36]$. Moreover, studies involving head-to-head colonoscopy and computed tomography (CT) colonography and tandem colonoscopy have demonstrated that colonoscopy misses some polyps $[37,38]$. In a systematic review of tandem colonoscopy studies, colonoscopy miss rates for polyps $\geq 10 \mathrm{~mm}, 6-9 \mathrm{~mm}$, and $<5 \mathrm{~mm}$ were found to be $2 \%, 13 \%$, and $26 \%$, respectively [37]. Endoscopist- and centre-related quality factors have been shown to predict a higher risk of interval CRC [39-41]. Endoscopists and endoscopic centres performing low quality examinations, as measured by adenoma/polyp detection rate and cecal intubation rate, have consistently been associated with a higher risk of post-colonoscopy interval CRC [39, 40,42]. In addition, the incomplete removal of lesions has consistently been shown to increase the subsequent risk of CRC $[16,23,43]$.

For these reasons, widespread implementation of quality assurance programmes is necessary for adequate efficacy of post-polypectomy surveillance. Factors associated with the quality of colonoscopy and of bowel cleansing have been reviewed in specific ESGE Guidelines $[44,45]$. There is no evidence that overutilization of endoscopic surveillance can compensate for an initially suboptimal colonoscopy. Moreover, to duplicate an invasive and costly procedure, rather than to address, for example, the quality of bowel cleansing and improved endoscopist training, seems unacceptable from the point of view of cost-effectiveness and patient acceptability. Briefly, high quality colonoscopies should be complete up to the caecum with a meticulous inspection of adequately cleaned colorectal mucosa. Neoplastic lesions should be completely removed (en bloc when feasible) and retrieved for histological examination. This does not contradict early repetition of the colonoscopy if the quality of the initial procedure was suboptimal because of inadequate bowel cleansing or other factors (see below in the specific scenarios, and $\bullet$ Table e1, available online).

\section{Appropriate scheduling of surveillance}

The ESGE recommends that the endoscopist is responsible for providing a written recommendation for the post-polypectomy surveillance schedule (strong recommendation, low quality evidence), and that this should be audited (weak recommendation, low quality evidence).

Surveillance colonoscopies represent a major part of all colonoscopies performed, being nearly $30 \%$ in a recent survey [46]. This proportion may increase with the widespread adoption of CRC screening programmes and with improved adenoma detection related to the use of high resolution colonoscopy and dye-spraying techniques $[3,47,48]$. For these reasons, the required capacity of colonoscopy services is heavily dependent on correct indications and timings for post-polypectomy surveillance [49-51]. Studies have shown that a large proportion of surveillance procedures are inappropriate in both selection of cases and timing of surveillance, representing both over- and underuse of surveillance [46, $51-58]$. In a recent survey, $69 \%$ of post-polypectomy surveillance procedures were inappropriate regarding either timing or indication [46]. In another study, over $40 \%$ of patients with small adenomas had an inappropriately early surveillance examination [52]. Moreover, surveillance is still recommended to patients with clinically irrelevant hyperplastic lesions who do not need any endoscopic surveillance [46, 52-58]. (See also - Table e2, available online).

Appropriateness of surveillance not only depends on the characteristics and number of completely removed polyps, but also on factors such as the quality of endoscopy, and the patient's age and life-expectancy. For these reasons, the endoscopist should be the professional who advises the patient on the appropriate surveillance interval. Since histology reports become available some time after the polypectomy, we recommend that the endoscopist updates and/or finalizes the endoscopy report after receiving the histology report; the updated colonoscopy report should include a written recommendation on the appropriate surveillance, taking into account all endoscopic, histological, and patient-related factors. Adherence to published surveillance guidelines should be monitored as part of a quality assurance programme [59-61].

\section{Low risk group}

In the low risk group (patients with 1-2 tubular adenomas $<10 \mathrm{~mm}$ with low grade dysplasia), the ESGE recommends participation in existing national screening programmes 10 years after the index colonoscopy. If no screening programme is available, repetition of colonoscopy 10 years after the index colonoscopy is recommended (strong recommendation, moderate quality evidence).

\section{Long-term CRC risk in low risk group (see 0 Table 3 a)}

Epidemiological studies have assessed long-term CRC incidence/ mortality risk in patients with 1-2 tubular adenomas $<10 \mathrm{~mm}$ with low grade dysplasia. In a retrospective study [62], including 1618 patients with adenomas resected by rigid sigmoidoscopy who did not undergo endoscopic surveillance, patients stratified to this low risk group had a similar risk of developing CRC compared with the general population (standardized incidence ratio [SIR] $0.5,95 \%$ confidence interval [CI] $0.1-1.3$ ). The same finding was reported in a registry-based study that included 5779 postpolypectomy patients: the low risk group did not have an increased risk of cancer despite the lack of surveillance (SIR 0.68, $95 \%$ CI 0.44-0.99) [18]. Furthermore, case - control studies have also confirmed a low long-term risk of CRC in these patients, with a more profound effect during the 5 years immediately following the index polypectomy $[22,23,63]$. A conservative policy of post-polypectomy endoscopic surveillance was recently tested and found to be adequate in two prospective screening sigmoidoscopy trials $[9,11]$.

Incidence of metachronous advanced neoplasia in the low risk group

Several cohort studies have compared the incidence of metachronous advanced adenomas between a low risk group and a control 
Table 3 Long-term colorectal cancer risk. a Studies reporting standardized incidence ratio (SIR) with $95 \%$ confidence intervals (CI) in low and high risk groups as compared with the general population.

\begin{tabular}{|llll}
\hline First author & Variable & Low risk & High risk \\
\hline Atkin $[62]$ & $\operatorname{SIR}(95 \% \mathrm{Cl})$ & $0.5(0.1-1.3)$ & $3.6(2.4-5.0)$ \\
\hline Cottet $[18]$ & $\operatorname{SIR}(95 \% \mathrm{Cl})$ & $0.8(0.4-1.5)$ & $4.3(2.9-6.0)$ \\
\hline
\end{tabular}

Table 3 Long-term colorectal cancer risk. b Studies comparing incidence (hazard ratio [HR] or risk ratio [RR]) of metachronous advanced neoplasia between low risk and high risk groups, and patients without neoplasia at baseline examination.

\begin{tabular}{|c|c|c|c|}
\hline First author & Variable & Low risk & High risk \\
\hline Yamaji [15] & $\mathrm{HR}(95 \% \mathrm{Cl})$ & Nonadvanced: $2.6(1.6-4.2)$ & Advanced: $6.6(3.7-12)$ \\
\hline Lieberman [35] & $\operatorname{RR}(95 \% \mathrm{Cl})$ & Tubular $<10 \mathrm{~mm}: 2.6(0.2-5.7)$ & $\begin{array}{l}\text { Tubular }>10 \mathrm{~mm}: 6.4(2.7-14.9) \\
\text { Villous pattern: } 6.1(2.5-14.7) \\
\text { High grade dysplasia: } 6.9(2.6-18.1)\end{array}$ \\
\hline Miller [66] & $\mathrm{RR}(95 \% \mathrm{Cl})$ & $\begin{array}{l}<5 \mathrm{~mm}: 1.1(0.4-3.3) \\
5-9 \mathrm{~mm}: 1.5(0.6-3.9) \\
\text { Tubular: } 0.9(0.4-2.3)\end{array}$ & $\begin{array}{l}\geq 10 \mathrm{mm:}: 2.1(1.3-2.7) \\
\text { Villous pattern: } 4.2(1.5-11.5)\end{array}$ \\
\hline Chung [64] & $\mathrm{HR}(95 \% \mathrm{Cl})$ & Nonadvanced: $1.1(0.6-2.2)$ & Advanced: 6.0 (3.7-9.7) \\
\hline
\end{tabular}

$\mathrm{Cl}$, confidence interval

group without adenoma at index colonoscopy [15,35,64-66] ( Table 3 b; see also $\bullet$ Table e4, available online). One study found a higher incidence of advanced neoplasia (hazard ratio [HR] 2.6; 95\%CI 1.6-4.2) in the low risk group compared with controls [15]. None of the other studies detected a statistically significant difference, either at 5 years $[35,64-66]$ or at $6-10$ years of follow-up $[65,66]$. Two randomized controlled trials (RCTs) [35, 67], as well as three cohort studies [64, 66,68], compared the prevalence of advanced neoplasia at different intervals between the index examination and the first surveillance colonoscopy in the low risk group. No statistically significant difference was found when comparing intervals of 2 vs 4 years, 3 vs 5 years, and $3-5$ vs $6-10$ years $[35,64,66,67,69]$.

\section{Timing of surveillance/return to screening in low risk group}

For individuals without increased risk of CRC (i.e., risk similar to that in the general population) a 10 -year interval before undergoing surveillance colonoscopy or returning to a screening programme appears to be justified by the long-term efficacy of lower gastrointestinal endoscopy (i.e., sigmoidoscopy or colonoscopy) as demonstrated in RCTs and case-control studies $[7,11,70]$

\section{High risk group}

In the high risk group (patients with adenomas with villous histology or high grade dysplasia or $\geq 10 \mathrm{~mm}$ in size, or $\geq 3$ adenomas), the ESGE recommends surveillance colonoscopy 3 years after the index colonoscopy (strong recommendation, moderate quality evidence). Patients with $\mathbf{1 0}$ or more adenomas should be referred for genetic counselling (strong recommendation, moderate quality evidence).

Long-term CRC risk in the high risk group (see 0 Table 3 a) Epidemiological studies have indicated that the high risk group is at increased risk of CRC compared with the general population. Patients stratified into the high risk group who were followed for 14 years (without endoscopic surveillance) had a 3.6 - to 6.6fold increase in CRC risk, compared with the general population [62]. Another study found that patients with advanced adenomas who did not undergo endoscopic surveillance had a 4.26 (95\%CI 2.89 - 6.04) times greater risk for CRC [18]. Epidemiological series also showed a high efficacy of endoscopic surveillance in reducing the CRC risk in the high risk group $[22,23,63]$.

\section{Incidence of metachronous advanced neoplasia in the} high risk group

In prospective cohort studies, the incidence of metachronous advanced neoplasia was 5-7 times higher in the high risk group compared with individuals without adenomas at the index colonoscopy $[15,35,64]$. A pooled analysis included individual data on 9167 participants from 8 prospective post-polypectomy trials with a mean follow-up of 47 months. The crude risk of advanced neoplasia during follow-up was $15.5 \%$ in the high risk group and $6.9 \%$ in the low risk group [32]. In a multivariate analysis, size, multiplicity, and presence of villous component of the baseline lesions appeared to be independent risk factors for metachronous advanced neoplasia, whilst high grade dysplasia was not [32]. These results were largely confirmed by two meta-analyses $[71,72]$. The risk of metachronous advanced lesions seems to be higher in the high risk groups, but the contribution of each individual unfavourable adenoma feature (size, multiplicity, villous component) was less consistent $[32,71,72]$. Further data on these individual factors in the high risk group are provided in $\bullet$ Table e4 and $\odot$ Table e5 (available online).

It has been suggested that individuals with 5 small adenomas, or 3 or more adenomas where at least one was $\geq 10 \mathrm{~mm}$, could benefit from endoscopic surveillance 1 year after the last endoscopy [73]. In a pooled analysis of 4 surveillance studies, including 3226 patients, these individuals had a doubled risk of metachronous advanced lesions compared with those in the high risk group who did not have these characteristics [73]. However, these individuals did not have higher risk of CRC, and there is considerable uncertainty about how this higher risk of advanced neoplasia may translate into CRC risk.

Timing of surveillance in the high risk group

In the US National Polyp Study, following adenoma resection 1418 patients were randomly allocated to either a 1-year followed by a 3-year surveillance colonoscopy or to a single 3-year surveillance colonoscopy. The incidence of advanced lesions was $3.3 \%$ in both groups [74]. In a retrospective observational study, 
the cumulative incidence of metachronous advanced neoplasia in the high risk group increased with increasing surveillance interval; after intervals of $1-3,3-5,5-10$ and $10-20$ years, the incidences of metachronous advanced neoplasia were $3.8 \%, 13.1 \%$, $34.7 \%$ and $52 \%$, respectively [68]. In contrast, another observational study found no association between the duration of the surveillance interval (from 0.5 to 10 years) and the risk of metachronous advanced neoplasia in the high risk group (the risk varied between $9.9 \%$ and $11.4 \%$ ) [65]. This finding was confirmed in a case - control study where the risk of CRC was unchanged if the surveillance interval was prolonged from 3 years to 5 years [75]. In line with current recommendations [76], we propose that individuals with 10 or more adenomas be referred for genetic counselling because of the risk of familial adenomatous polyposis (FAP) or other genetic diseases, such as MYH-associated polyposis. Tailored surveillance programmes for patients with hereditary colorectal cancer syndromes are outside the scope of this guideline.

In the high risk group, if no high risk adenomas are detected at the first surveillance examination, the ESGE suggests a 5-year interval before a second surveillance colonoscopy (weak recommendation, low quality evidence). If high risk adenomas are detected at first or subsequent surveillance examinations, a 3-year repetition of surveillance colonoscopy is recommended (strong recommendation, low quality evidence). The ESGE found insufficient evidence to give recommendations in the case where no high risk adenomas are detected during 2 consecutive surveillance colonoscopies. However, intervals longer than 5 years appear reasonable (very low quality evidence).

Three recent cohort studies have investigated the risk of metachronous advanced lesions at second surveillance colonoscopy, according to the findings at the baseline and first surveillance colonoscopy $[65,77,78]$ ( Table e6, available online). The study designs were prone to selection bias because of nonadherence, which might affect generalizability. However, despite heterogeneity in the study populations, results were reassuringly consistent across the studies. In individuals with high risk adenomas at the index colonoscopy and no high risk adenomas at the first surveillance endoscopy, the risk of metachronous advanced neoplasia at the second surveillance colonoscopy was higher than among individuals without high risk adenomas detected at the index colonoscopy $[65,77,78]$. The absolute risk of metachronous advanced neoplasia at the second surveillance colonoscopy was $5.9 \%-6.7 \%$ among individuals with high risk adenomas at the index colonoscopy, and 3.1\%-5.7\% among individuals without high risk adenomas $[65,77,78]$. This supports the recommendation of a second surveillance colonoscopy after 5 years. For individuals with high risk adenomas detected at endoscopic surveillance, the risk of metachronous advanced neoplasia was higher than for individuals without high risk adenomas, regardless of the findings at previous examinations. The absolute risk for metachronous advanced neoplasia at second surveillance endoscopy ranged from $11.5 \%$ to $19.3 \%$ for individuals with high risk adenomas at first surveillance colonoscopy $[65,77,78]$. In comparison, the risk varied from $3.1 \%$ to $6.7 \%$ for individuals without advanced neoplasia at first surveillance $[65,77,78]$. No study addressed the risk of metachronous advanced neoplasia after two surveillance colonoscopies without high risk adenomas. When considering the progressive decrease in the incidence of such lesions at the first two surveillance colonoscopies, intervals longer than 5 years may appear reasonable.
Serrated polyps (see also Table e7, available online) The ESGE recommends that patients with serrated polyps $<10 \mathrm{~mm}$ in size with no dysplasia should be classified as low risk (weak recommendation, low quality evidence). The ESGE suggests that patients with large serrated polyps ( $\geq 10 \mathrm{~mm}$ ) or those with dysplasia should be classified as high risk (weak recommendation, low quality evidence).

Patients with 5 or more serrated polyps proximal to the sigmoid, of which 2 or more are sized $\geq 10 \mathrm{~mm}$, or with 20 or more serrated polyps of any size but distributed throughout the colon, meet the World Health Organization criteria for serrated polyposis and should be referred for genetic counselling (strong recommendation, low quality evidence).

Serrated polyps are classified into different subgroups: (i) hyperplastic polyps, (ii) sessile serrated polyps, (iii) mixed polyps, and (iv) traditional serrated adenomas. No prospective study has yet assessed the long-term risk of CRC in patients with neoplastic and non-neoplastic serrated lesions, leading to uncertainty on the usefulness of endoscopic surveillance.

\section{Hyperplastic polyps}

Observational studies found that in the absence of any neoplasia, hyperplastic polyps are not associated with advanced adenomas $[79,80]$, although a slightly increased risk of adenomas was found $[81,82]$. The coexistence of hyperplastic polyps with adenomas at index colonoscopy does not increase the risk of adenomas and advanced adenomas at surveillance compared with adenomas alone [81-83]. Indirect evidence of the indolent behavior of hyperplastic polyps is also found in sigmoidoscopy and colonoscopy studies $[13,79]$.

\section{Sessile serrated polyps (also defined as sessile serrated adenomas/lesions)}

One retrospective pathology-based study showed that $15 \%$ of patients with sessile serrated polyps at index examination developed advanced neoplasia (CRC/HGD) within approximately 8 years of follow-up, compared with $5.5 \%$ of patients with baseline adenomas within 3 years of follow-up [80]. However, the difference in follow-up durations generates some uncertainty about such a comparison [80]. Another study demonstrated that in $50 \%$ of patients with sessile serrated polyps at baseline, subsequent sessile serrated polyps were detected within approximately 3 years of follow-up [84]. However, patients with nondysplastic sessile serrated polyps did not present an increased risk of metachronous advanced neoplasia, although size $\geq 10 \mathrm{~mm}$ or proximal location were predictors of synchronous advanced neoplasia [85, 86]. In particular, large serrated polyps were associated with a higher risk of proximal CRC [86]. Three studies have found an association between type of lesion detected during follow-up and type of lesions found at baseline colonoscopy $[84,87,88]$. Patients with sessile serrated lesions are more likely to develop further sessile serrated lesions. However, there is no evidence of an increased risk of metachronous CRC $[84,87,88]$. We recommend that some patients, who fulfil the WHO criteria for serrated polyposis syndrome, should be considered for genetic counselling [89]. This includes: (i) individuals with 5 or more serrated polyps proximal to the sigmoid with 2 or more of those being $\geq 10 \mathrm{~mm}$ in diameter, and (ii) individuals with 20 or more serrated polyps of any size distributed throughout the colon (both right- and leftsided). 


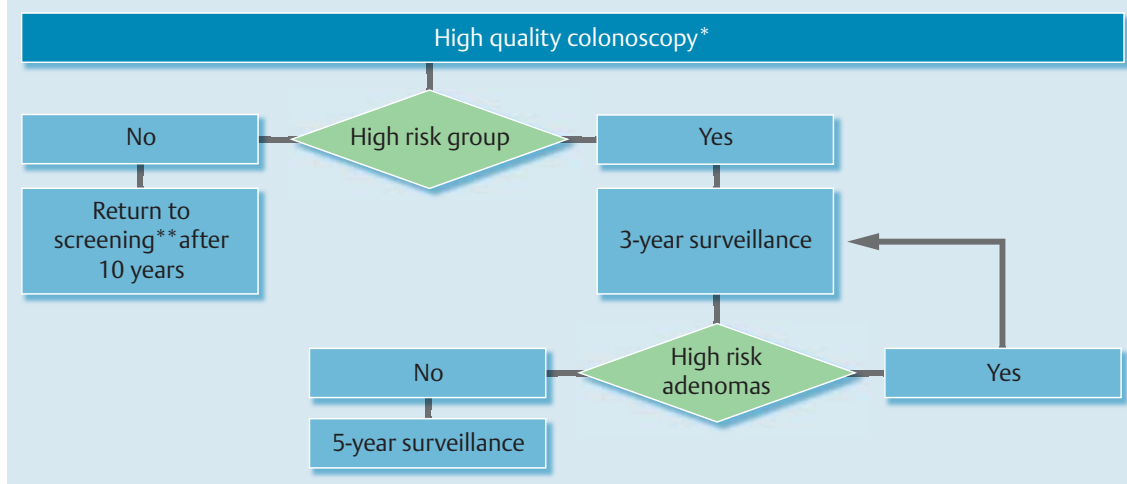

Fig. 1 Dichotomization of patients following a high quality colonoscopy in which high risk lesions have or have not been detected. High risk group: patients with an adenoma $\geq 10 \mathrm{~mm}$; or with high grade dysplasia; or a villous component or $\geq 3$ adenomas; serrated polyp $\geq 10 \mathrm{~mm}$ or with dysplasia. * Excluding those in whom cancer has already developed. ** To a screening programme if available, otherwise to repetition of colonoscopy.

Mixed polyps and traditional serrated adenomas

Sessile serrated lesions that harbour an adenomatous component are called mixed polyps [90]. These lesions present with a dysplastic component, analogously to the traditional serrated adenomas. No data exist regarding the incidence of metachronous advanced lesions.

Since most pathologists do not yet correctly classify serrated lesions into the several subtypes, we have preferred not to subclassify such lesions for the purposes of our statement [91].

\section{Specific scenarios}

In the case of piecemeal resection of adenomas larger than $10 \mathrm{~mm}$, endoscopic follow-up within 6 months is recommended before the patient is entered into a surveillance programme (strong recommendation, moderate quality evidence).

Incomplete removal of larger neoplastic lesions must be ruled out before an endoscopic surveillance schedule is recommended $(\bullet$ Table e1c and d, available online). Recently, inadequate polypectomy has been reported in up to $17 \%$ of lesions $\geq 10 \mathrm{~mm}$, especially if piecemeal polypectomy had been performed [92]. Incomplete excision of neoplastic lesions has been consistently shown to increase the risk of post-colonoscopy interval CRC [43]. For this reason, an early follow-up of these lesions is recommended within 6 months ( $\bullet$ Table e $1 \mathbf{b}$, available online), even if the resection was apparently complete on the basis of endoscopic and histologic criteria [92, 93]. Normal macroscopic appearance of the polypectomy site and negative scar biopsy specimens at the first follow-up have been shown to be predictive of long-term eradication [93].

The ESGE found insufficient evidence to provide recommendations on post-polypectomy surveillance based on other potential risk factors, such as age, or family history of CRC (very low quality evidence). However, it seems reasonable to stop endoscopic surveillance at 80 years, or earlier depending on life expectancy (in the case of co-morbidities).

A pooled analysis showed that age was a strong risk factor for metachronous advanced neoplasia. The risk was almost three times higher among individuals older than 80 years compared with those between 50 and 59 years (OR 2.7; 95\%CI 1.3-5.6) [94]. Conversely, there was no significant difference between individuals aged 50 to 59 and those aged 60 to 69 [64]. Older people could be more prone to complications of colonoscopy, and the potential benefit of endoscopic surveillance may be limited by reduced life expectancy, especially when the estimated 10-20year duration of the traditional adenoma-carcinoma sequence is taken into account. No studies have assessed the optimal age for stopping surveillance. Although statistical simulations indi- cate that surveillance should be stopped between 75 and 85 years, this needs to be confirmed by future trials [95]. Therefore, individualized recommendations should be based on general health status, comorbidity and the findings at previous colonoscopies [96]. It is likely that individuals with limited life expectancy (i.e., shorter than 10 years) will not benefit from post-polypectomy endoscopic surveillance $[95,96]$.

A recent meta-analysis reviewed the influence of family history on the incidence of metachronous advanced neoplasia [97]. In all studies, including 21595 participants, a positive family history was defined as having at least one first-degree relative with CRC (parents, siblings, or children) $[64,94,98,99]$. None of the studies assessed the influence of family history stratified by age at diagnosis and the number of relatives with CRC. The proportion of participants with a positive family history of CRC ranged between $4.9 \%$ and $27.5 \%[64,99]$. No association was found between firstdegree family history of CRC and metachronous advanced neoplasia (OR $1.20,95 \% \mathrm{CI} 0.96-1.50$ ). Similarly, race/ethnicity did not appear to predict rate of metachronous advanced adenoma at endoscopic surveillance [100].

The ESGE recommends an early repetition of colonoscopy or a shorter surveillance interval in patients in whom an optimal inspection of colorectal mucosa has been hampered by an inadequate preparation, especially if neoplastic lesions have been detected in the initial examination.

An inadequate level of bowel preparation has been associated with a reduced detection of neoplastic lesions and, therefore, with a higher risk of missed lesions ( $\bullet$ Table e1 a, available online) [101-103]. It has also been shown to be a strong risk factor for metachronous advanced adenoma at surveillance [104]. Thus, early repetition of colonoscopy seems advisable. For instance, if no high risk lesions have been detected and a sufficient level of mucosal inspection has been achieved (i.e., allowing reasonable exclusion of the presence of lesions $\geq 5 \mathrm{~mm}$ ), rather than 10 years before the subsequent screening colonoscopy, a 5 -year interval has been suggested [60]. When repeating colonoscopy or shortening the surveillance interval, all the recommendations for an adequate bowel preparation, including split regimen, must be followed [45].

The ESGE recommends against the use of interval faecal occult blood tests (FOBTs) for post-polypectomy surveillance (strong recommendation, low quality evidence). In the case of an unplanned positive FOBT, the decision to repeat colonoscopy should be based on clinical judgment (weak recommendation, low quality evidence). 
The risk of metachronous CRC in patients following polypectomy is stratified by the findings at the index colonoscopy. For this reason, the attempt to re-stratify risk of CRC by applying a guaiacfaecal occult blood test/faecal immunochemical test (g-FOBT/ FIT) would appear to be mere duplication. Although interval CRC may be detected by g-FOBT/FIT, the expected low prevalence of disease would result in a high false-positive rate and a substantial burden on personal, endoscopic, and economic resources. In two nonrandomized studies including high risk individuals, a total of 1856 participants underwent at least one interval FIT during a colonoscopy-based CRC screening programme $[105,106]$. Colonoscopy was performed in 454 FIT-positive individuals; it led to detection of 18 CRCs, giving a positive predictive value of $4 \%$ which is dramatically lower than in a primary FIT screening setting [107]. Unplanned FOBT, although recommended against, may turn out to be positive. The decision whether or not to repeat a colonoscopy should depend on careful clinical evaluation, including the quality of the latest colonoscopy, and the time interval between the latest colonoscopy and FOBT.

The ESGE suggests that individuals with symptoms in the surveillance interval should be managed as clinically indicated (weak recommendation, low quality evidence).

Patients under appropriate surveillance are at low risk of CRC but interval CRC may develop, whether polypectomy has been done or not $[5,16]$. Thus, repetition of colonoscopy should be considered if there is clinical suspicion of interval CRC.

\section{Discussion}

Following a high quality colonoscopy with no detection of CRC, patients may be simply dichotomized according to the presence or absence of high risk adenomatous and serrated colorectal lesions ( $\bullet$ Fig. 1). Endoscopic surveillance is recommended for individuals in the high risk group ( $\bullet$ Box 1$)$. Surveillance is not indicated for individuals in the low risk group, as with individuals with normal colonoscopy findings, for whom return to screening after 10 years is recommended. This simple approach eliminates confusion about the timing of surveillance colonoscopy, and optimizes the utilization of endoscopic resources. Nevertheless, it offers intensive surveillance, i.e., 3 colonoscopies over 10 years, to individuals who are the most likely to benefit from this.

The main difference between the ESGE and the recent US MultiSociety Task Force (MSTF) post-polypectomy Guidelines is the American recommendation for 5-10-year endoscopic surveillance in the low risk group [60]. The main reason for the 5-year US-MSTF recommendation is the possibility of inadequate preparation or poor quality endoscopic examination. We excluded low quality colonoscopy from the scope of our main recommendations. However, in the specific scenarios, we also allowed the possibility of shortening the interval to the next screening colonoscopy in the case of inadequate bowel preparation. There is insufficient evidence regarding the appropriate surveillance interval after a suboptimal colonoscopy, and we want to emphasize the need to repeat colonoscopy as soon as is practicable in the case of a suboptimal examination. In contrast to the ESGE recommendations, the European quality assurance guidelines propose that the first surveillance in patients with 5 polyps or more or with adenoma $\geq 20 \mathrm{~mm}$ should be after 1 year rather than 3 years. However, the evidence to underpin this advice does not appear firm [61]. In particular, these patients do not show a high- er risk of incident CRC, whilst it is unlikely that the moderate increase in the risk of advanced adenoma may represent a significant cause of morbidity/mortality in the subsequent 2 years of follow-up [32,61]. Moreover, our Guideline already recommends that patients with an adenoma $\geq 10 \mathrm{~mm}$ that was removed piecemeal should have a 6-month surveillance, according to our guideline.

Overall, discrepancies among the main recommendations of different societies seem to be related to the quality of the supporting studies. It should be remembered that most of these studies were carried out before the advent of high resolution colonoscopy and before quality assurance had been incorporated into clinical practice [32].

There is little consistency in the surveillance recommendations for patients with serrated polyps [60,61], because of the lack of firm data on the risk of subsequent polyps and CRC in these patients. However, because of the consistently higher risk of synchronous advanced neoplasia in patients with large serrated polyps, we preferred to recommend a prudent approach until more definitive evidence becomes available.

The ESGE Guideline provides an evidence-based risk-stratification strategy for post-polypectomy surveillance, limiting surveillance to patients with a greater CRC risk. This approach husbands resources whilst maximizing benefits. Such an approach seems of critical importance when the progressive implementation of CRC screening programs throughout Europe is considered. Further studies in this field, especially dealing with serrated lesions, are needed ( $\bullet$ Table e8, available online).

ESGE guidelines represent a consensus of best practice based on the available evidence at the time of preparation. They may not apply in all situations and should be interpreted in the light of specific clinical situations and resource availability. Further controlled clinical studies may be needed to clarify aspects of these statements, and revision may be necessary as new data appear. Clinical consideration may justify a course of action at variance to these recommendations. ESGE guidelines are intended to be an educational device to provide information that may assist endoscopists in providing care to patients. They are not rules and should not be construed as establishing a legal standard of care or as encouraging, advocating, requiring, or discouraging any particular treatment.

Competing interests: E. Dekker: Research grant and equipment on loan from Olympus Europe

\section{Institutions}

${ }^{1}$ Digestive Endoscopy Unit, Catholic University, Rome, Italy

${ }^{2}$ Gastroenterology Department, Hospital Universitario de Canarias-La Laguna University, Spain

${ }^{3}$ Oncology Group, Asociación Española de Gastroenterología, Spain

${ }^{4}$ Division of Gastroenterology and Hepatology, Geneva University Hospitals; Geneva, Switzerland

${ }^{5}$ Department of Gastroenterology, Maria Sklodowska-Curie Memorial Cancer Center and Medical Centre for Postgraduate Education, Warsaw, Poland ${ }^{6}$ Gastroenterology Department, Oporto Oncology Institute, Oporto, Portugal 7 Department of Gastroenterology, Cochin Hospital, Paris, France

${ }^{8}$ Department of Gastroenterology and Hepatology, Academic Medical Center, Amsterdam, The Netherlands

${ }^{9}$ Department of Internal Medicine III, Division of Gastroenterology and Hepatology, Medical University of Vienna, Vienna, Austria. 
${ }^{10}$ Gastroenterology Department, Hospital General Universitario de Alicante, Spain

${ }^{11}$ Department of Clinical Research, Telemark Hospital, Skien, Norway

${ }^{12}$ Department of Health Management and Health Economics, Institute of Health and Society, University of Oslo, Oslo, Norway

${ }^{13}$ Division of Cancer Medicine, Surgery and Transplantation, Oslo University Hospital, Oslo, Norway

${ }^{14}$ Department of Medicine, Ruhr-Universität Bochum, Knappschaftskrankenhaus, Bochum, Germany

${ }^{15}$ Centre for Digestive Diseases, The General Infirmary at Leeds, Leeds, United Kingdom

${ }^{16}$ Oregon Health and Science University, Portland, Oregon

\section{References}

1 Ferlay J, Autier P, Boniol $M$ et al. Estimates of the cancer incidence and mortality in Europe in 2006. Ann Oncol 2007; 18: 581-592. Epub 2007 Feb 7

2 Edwards BK, Ward E, Kohler BA et al. Annual report to the nation on the status of cancer, 1975-2006, featuring colorectal cancer trends and impact of interventions (risk factors, screening, and treatment) to reduce future rates. Cancer 2010; 116: 544-573

3 Joseph DA, King JB, Miller JW et al. Prevalence of colorectal cancer screening among adults - Behavioral Risk Factor Surveillance System, United States, 2010. MMWR Morb Mortal Wkly Rep 2012; 61: 51 - 56

4 Winawer SJ, Zauber AG, Ho MN. The National Polyp Study Workgroup. et al. Prevention of colorectal cancer by colonoscopic polypectomy. N Engl J Med 1993; 329: 1977-1981

5 Baxter NN, Goldwasser MA, Paszat LF et al. Association of colonoscopy and death from colorectal cancer. Ann Intern Med 2009; 150: 1 -8

6 Hewitson P, Glasziou P, Irwig $L$ et al. Screening for colorectal cancer using the faecal occult blood test, hemoccult. Cochrane Database Syst Rev 2007 Jan 24: 01CD001216

7 Atkin WS, Edwards R, Kralj-Hans I et al. Once-only flexible sigmoidoscopy screening in prevention of colorectal cancer: a multicentre randomised controlled trial. Lancet 2010; 375: 1624-1633

8 von Karsa L, Patnick J, Segnan N. European guidelines for quality assurance in colorectal cancer screening and diagnosis. First Edition Executive summary. Endoscopy 2012; 44: 03 E1-8

9 Atkin W, Kralj-Hans I, Wardle J et al. Colorectal cancer screening. Randomised trials of flexible sigmoidoscopy. BMJ 2010; 341: c4618

10 Kahi CJ, Imperiale TF, Juliar BE et al. Effect of screening colonoscopy on colorectal cancer incidence and mortality. Clin Gastroenterol Hepatol 2009; 7: 770 - 775; quiz 711. Epub 2009 Jan 11

11 Segnan N, Armaroli P, Bonelli L et al. Once-only sigmoidoscopy in colorectal cancer screening: follow-up findings of the Italian Randomized Controlled Trial - SCORE. J Natl Cancer Inst 2011; 103: 1310-1322. Epub 2011 Aug 18

12 Lieberman DA, Weiss DG, Bond JH. Veterans Affairs Cooperative Study Group 380. et al. Use of colonoscopy to screen asymptomatic adults for colorectal cancer. N Engl J Med 2000; 343: 162 - 168

13 Imperiale TF, Wagner DR, Lin CY et al. Risk of advanced proximal neoplasms in asymptomatic adults according to the distal colorectal findings. N Engl J Med 2000; 343: 169-174

14 Bretthauer $M$, Kalager $M$. Colonoscopy as a triage screening test. N Engl J Med 2012; 366: 759-760

15 Yamaji Y, Mitsushima T, Ikuma $H$ et al. Incidence and recurrence rates of colorectal adenomas estimated by annually repeated colonoscopies on asymptomatic Japanese. Gut 2004; 53: 568 - 572

16 Robertson DJ, Greenberg ER, Beach $M$ et al. Colorectal cancer in patients under close colonoscopic surveillance. Gastroenterology 2005; 129: $34-41$

17 Loeve F, van Ballegooijen $M$, Boer $R$ et al. Colorectal cancer risk in adenoma patients: a nation-wide study. Int J Cancer 2004; 111: 147-151

18 Cottet $V$, Jooste $V$, Fournel I et al. Long-term risk of colorectal cancer after adenoma removal: a population-based cohort study. Gut 2012; 61: $1180-1186$

19 Rex DK, Cutler CS, Lemmel GT et al. Colonoscopic miss rates of adenomas determined by back-to-back colonoscopies. Gastroenterology 1997; $112: 24-28$

20 Anti M, Armuzzi A, Morini S et al. Severe imbalance of cell proliferation and apoptosis in the left colon and in the rectosigmoid tract in subjects with a history of large adenomas. Gut 2001; 48: 238-246

21 Atkin WS, Morson BC, Cuzick J. Long-term risk of colorectal cancer after excision of rectosigmoid adenomas. N Engl J Med 1992; 326: $658-662$
22 Brenner H, Chang-Claude J, Rickert A et al. Risk of colorectal cancer after detection and removal of adenomas at colonoscopy: population-based case-control study. J Clin Oncol 2012; 30: 2969-2976

23 Brenner H, Chang-Claude J, Jansen L et al. Role of colonoscopy and polyp characteristics in colorectal cancer after colonoscopic polyp detection: a population-based case-control study. Ann Intern Med 2012; 157: 225-232

24 Regula J, Rupinski M, Kraszewska E et al. Colonoscopy in colorectalcancer screening for detection of advanced neoplasia. N Engl J Med 2006; 355: $1863-1872$

25 Hassan C, Pickhardt PJ, Kim DH et al. Systematic review: distribution of advanced neoplasia according to polyp size at screening colonoscopy. Aliment Pharmacol Ther 2010; 31: 210-217

26 Gupta N, Bansal A, Rao D et al. Prevalence of advanced histological features in diminutive and small colon polyps. Gastrointest Endosc 2012; 75: $1022-1030$

27 Kahi CJ, Hewett DG, Norton DL et al. Prevalence and variable detection of proximal colon serrated polyps during screening colonoscopy. Clin Gastroenterol Hepatol 2011; 9: 42 - 46

28 Radaelli F, Paggi S, Bortoli A et al. Overutilization of post-polypectomy surveillance colonoscopy in clinical practice: a prospective, multicentre study. Dig Liver Dis 2012; 44: 748 - 753. Epub 2012 May 22

29 Rex DK, Overhiser AJ, Chen SC et al. Estimation of impact of American College of Radiology recommendations on CT colonography reporting for resection of high-risk adenoma findings. Am J Gastroenterol 2009; 104: 149-153

30 Lieberman DA, Holub J, Eisen G et al. Utilization of colonoscopy in the United States: results from a national consortium. Gastrointest Endosc 2005; 62: 875-883

31 Levin TR, Zhao W, Conell $C$ et al. Complications of colonoscopy in an integrated health care delivery system. Ann Intern Med 2006; 145 : $880-886$

32 Martinez ME, Baron JA, Lieberman DA et al. A pooled analysis of advanced colorectal neoplasia diagnoses after colonoscopic polypectomy. Gastroenterology 2009; 136: $832-841$

33 Dumonceau J-M, Hassan C, Riphaus A et al. European Society of Gastrointestinal Endoscopy (ESGE) Guideline Development Policy. Endoscopy 2012; 44: 629-629. Epub 2012 Feb 27

34 Zauber AG, Winawer SJ, O'Brien MJ et al. Colonoscopic polypectomy and long-term prevention of colorectal-cancer deaths. N Engl J Med 2012; 366: 687-696

35 Lieberman DA, Weiss DG, Harford $W V$ et al. Five-year colon surveillance after screening colonoscopy. Gastroenterology 2007; 133: $1077-1085$

36 Singh $H$, Turner D, Xue $L$ et al. Risk of developing colorectal cancer following a negative colonoscopy examination: evidence for a 10 -year interval between colonoscopies. JAMA 2006; 295: 2366 - 2373

37 van Rijn JC, Reitsma JB, Stoker J et al. Polyp miss rate determined by tandem colonoscopy: a systematic review. Am J Gastroenterol 2006; 101: $343-350$

38 Pickhardt PJ, Nugent PA, Mysliwiec PA et al. Location of adenomas missed by optical colonoscopy. Ann Intern Med 2004; 141: 352 - 359

39 Kaminski MF, Regula J, Kraszewska E et al. Quality indicators for colonoscopy and the risk of interval cancer. N Engl J Med 2010; 362: $1795-1803$

40 Cooper GS, Xu F, Barnholtz Sloan JS et al. Prevalence and predictors of interval colorectal cancers in medicare beneficiaries. Cancer 2012; 118: $3044-3052$

41 Baxter NN, Sutradhar R, Forbes SS et al. Analysis of administrative data finds endoscopist quality measures associated with postcolonoscopy colorectal cancer. Gastroenterology 2011; 140: 65- 72

42 Rogal SS, Pinsky PF, Schoen RE. Relationship between detection of adenomas by flexible sigmoidoscopy and interval distal colorectal cancer. Clin Gastroenterol Hepatol 2013; 11: 73 - 78 . Epub 2012 Aug 16

43 Pabby A, Schoen RE, Weissfeld JL et al. Analysis of colorectal cancer occurrence during surveillance colonoscopy in the dietary Polyp Prevention Trial. Gastrointest Endosc 2005; 61: 385 - 391

44 Rembacken B, Hassan C, Riemann JF et al. Quality in screening colonoscopy: position statement of the European Society of Gastrointestinal Endoscopy (ESGE). Endoscopy 2012; 44: 957-968

45 Hassan C, Bretthauer M, Kaminski MF et al. Bowel preparation for colonoscopy: European Society of Gastrointestinal Endoscopy (ESGE) Guideline. Endoscopy 2013; 45: 142-155 
46 Petruzziello L, Hassan C, Alvaro D et al. Appropriateness of the indication for colonoscopy: is the endoscopist the 'gold standard'? J Clin Gastroenterol 2012; 46: 590-594

47 Stock C, Brenner $H$. Utilization of lower gastrointestinal endoscopy and fecal occult blood test in 11 European countries: evidence from the Survey of Health, Aging and Retirement in Europe (SHARE). Endoscopy 2010; 42: 546-556

48 Rastogi A, Early DS, Gupta $N$ et al. Randomized, controlled trial of standard-definition white-light, high-definition white-light, and narrow-band imaging colonoscopy for the detection of colon polyps and prediction of polyp histology. Gastrointest Endosc 2011; 74: $593-$ 602

49 Morini S, Minoli G, Hassan C et al. The inappropriate use of colonoscopy in an open-access setting: A prospective multicenter study. Gastrointest Endosc 2000; 51: Ab86

50 Froehlich F, Pache I, Burnand B et al. Performance of panel-based criteria to evaluate the appropriateness of colonoscopy: a prospective study. Gastrointest Endosc 1998; 48: 128-136

51 Gimeno Garcia AZ, Gonzalez Y, Quintero E et al. Clinical validation of the European Panel on the Appropriateness of Gastrointestinal Endoscopy (EPAGE) II criteria in an open-access unit: a prospective study. Endoscopy 2012; 44: $32-37$

52 Schoen RE, Pinsky PF, Weissfeld JL et al. Utilization of surveillance colonoscopy in community practice. Gastroenterology 2010; 138: $73-$ 81

53 Mysliwiec PA, Brown ML, Klabunde CN et al. Are physicians doing too much colonoscopy? A national survey of colorectal surveillance after polypectomy Ann Intern Med 2004; 141: 264-271

54 Boolchand $V$, Olds $G$, Singh $J$ et al. Colorectal screening after polypectomy: a national survey study of primary care physicians. Ann Intern Med 2006; 145: 654-659

55 Saini SD, Nayak RS, Kuhn L et al. Why don't gastroenterologists follow colon polyp surveillance guidelines? results of a national survey J Clin Gastroenterol 2009; 43: 554-558

56 Ransohoff DF, Yankaskas B, Gizlice Z et al. Recommendations for postpolypectomy surveillance in community practice. Dig Dis Sci 2011; 56: $2623-2630$

57 Morini S, Hassan C, Meucci G et al. Diagnostic yield of open access colonoscopy according to appropriateness. Gastrointest Endosc 2001; 54: $175-179$

58 Chan TH, Goh KL. Appropriateness of colonoscopy using the ASGE guidelines: experience in a large Asian hospital. Chin J Dig Dis 2006; 7: $24-32$

59 Lieberman $D$, Nadel $M$, Smith $R A$ et al. Standardized colonoscopy reporting and data system: report of the Quality Assurance Task Group of the National Colorectal Cancer Roundtable. Gastrointest Endosc 2007; 65: 757-766

60 Lieberman DA, Rex DK, Winawer SJ et al. Guidelines for colonoscopy surveillance after screening and polypectomy: a consensus update by the US Multi-Society Task Force on Colorectal Cancer. Gastroenterology 2012; 143: 844-857

61 Atkin WS, Valori R, Kuipers EJ et al. European guidelines for quality assurance in colorectal cancer screening and diagnosis. First Edition Colonoscopic surveillance following adenoma removal. Endoscopy 2012; 44: 03 E151-163

62 Atkin WS, Morson BC, Cuzick J. Long-term risk of colorectal cancer after excision of rectosigmoid adenomas. N Engl J Med 1992; 326: $658-662$

63 Brenner H, Chang-Claude J, Seiler CM et al. Case-control study supports extension of surveillance interval after colonoscopic polypectomy to at least 5 yr. Am J Gastroenterol 2007; 102: 1739-1744

64 Chung SJ, Kim YS, Yang SY et al. Five-year risk for advanced colorectal neoplasia after initial colonoscopy according to the baseline risk stratification: a prospective study in 2452 asymptomatic Koreans. Gut 2011; 60: 1537-1543

65 Pinsky PF, Schoen RE, Weissfeld JL et al. The yield of surveillance colonoscopy by adenoma history and time to examination. Clin Gastroenterol Hepatol 2009; 7: 86-92

66 Miller HL, Mukherjee R, Tian J et al. Colonoscopy surveillance after polypectomy may be extended beyond five years. J Clin Gastroenterol 2010; 44: e162-166

67 Jorgensen OD, Kronborg O, Fenger C. A randomized surveillance study of patients with pedunculated and small sessile tubular and tubulovillous adenomas. The Funen Adenoma Follow-up Study. Scand J Gastroenterol 1995; 30: 686-692
68 Huang Y, Gong W, Su B et al. Recurrence and surveillance of colorectal adenoma after polypectomy in a southern Chinese population. J Gastroenterol 2010; 45: 838-845

69 Huang Y, Gong W, Su B et al. Risk and cause of interval colorectal cancer after colonoscopic polypectomy. Digestion 2012; 86: 148 - 154

70 Brenner H, Chang-Claude J, Seiler CM et al. Does a negative screening colonoscopy ever need to be repeated? Gut 2006; 55: 1145-1150

71 Saini SD, Kim HM, Schoenfeld P. Incidence of advanced adenomas at surveillance colonoscopy in patients with a personal history of colon adenomas: a meta-analysis and systematic review. Gastrointest Endosc 2006; 64: 614-626

72 de Jonge V, Sint Nicolaas J, van Leerdam ME et al. Systematic literature review and pooled analyses of risk factors for finding adenomas at surveillance colonoscopy. Endoscopy 2011; 43: 560-572

73 Martinez ME, Thompson P, Messer K et al. One-year risk for advanced colorectal neoplasia: U.S. versus U.K. risk-stratification guidelines. Ann Intern Med 2012; 157: 856-864

74 Winawer SJ, Zauber AG, O'Brien MJ. The National Polyp Study Workgroup. et al. Randomized comparison of surveillance intervals after colonoscopic removal of newly diagnosed adenomatous polyps. $\mathrm{N}$ Engl J Med 1993; 328: 901 -906

75 Brenner H, Haug U, Arndt V et al. Low risk of colorectal cancer and advanced adenomas more than 10 years after negative colonoscopy. Gastroenterology 2010; 138: 870-876

76 Jasperson KW, Tuohy TM, Neklason DW et al. Hereditary and familial colon cancer. Gastroenterology 2010; 138: 2044-2058

77 Laiyemo AO, Pinsky PF, Marcus PM et al. Utilization and yield of surveillance colonoscopy in the continued follow-up study of the polyp prevention trial. Clin Gastroenterol Hepatol 2009; 7: 562 - 567; quiz 497

78 Robertson DJ, Burke CA, Welch HG et al. Using the results of a baseline and a surveillance colonoscopy to predict recurrent adenomas with high-risk characteristics. Ann Intern Med 2009; 151: 103 - 109

79 Lieberman $D A$, Prindiville $S$, Weiss $D G$ et al. Risk factors for advanced colonic neoplasia and hyperplastic polyps in asymptomatic individuals. JAMA 2003; 290: 2959-2967

80 Lu FI, van Niekerk de W, Owen D et al. Longitudinal outcome study of sessile serrated adenomas of the colorectum: an increased risk for subsequent right-sided colorectal carcinoma. Am J Surg Pathol 2010; 34: 927-934

81 Imperiale TF, Glowinski EA, Lin-Cooper C et al. Five-year risk of colorectal neoplasia after negative screening colonoscopy. N Engl J Med 2008; 359: $1218-1224$

82 Schreiner MA, Weiss DG, Lieberman DA. Proximal and large hyperplastic and nondysplastic serrated polyps detected by colonoscopy are associated with neoplasia. Gastroenterology 2010; 139: 1497-1502

83 Laiyemo AO, Murphy G, Sansbury LB et al. Hyperplastic polyps and the risk of adenoma recurrence in the polyp prevention trial. Clin Gastroenterol Hepatol 2009; 7: $192-197$

84 Teriaky A, Driman DK, Chande N. Outcomes of a 5-year follow-up of patients with sessile serrated adenomas. Scand J Gastroenterol 2012; 47: 178-183

85 Schreiner MA, Weiss DG, Lieberman DA. Proximal and large hyperplastic and nondysplastic serrated polyps detected by colonoscopy are associated with neoplasia. Gastroenterology 2010; 139: 1497-1502

86 Hiraoka S, Kato J, Fujiki S et al. The presence of large serrated polyps increases risk for colorectal cancer. Gastroenterology 2010; 139: 1503 - 1510, 1510.e1 - 3. Epub 2010 Jul 16

87 Lazarus $R$, Junttila OE, Karttunen TJ et al. The risk of metachronous neoplasia in patients with serrated adenoma. Am J Clin Pathol 2005; 123: $349-359$

88 Salaria SN, Streppel MM, Lee LA et al. Sessile serrated adenomas: highrisk lesions? Hum Pathol 2012; 43: 1808 - 1814

89 Chow E, Lipton L, Lynch E et al. Hyperplastic polyposis syndrome: phenotypic presentations and the role of MBD4 and MYH. Gastroenterology 2006; 131: 30 - 39

90 Sheridan TB, Fenton H, Lewin MR et al. Sessile serrated adenomas with low- and high-grade dysplasia and early carcinomas: an immunohistochemical study of serrated lesions "caught in the act". Am J Clin Pathol 2006; 126: 564-571

91 Terdiman JP, McQuaid KR. Surveillance guidelines should be updated to recognize the importance of serrated polyps. Gastroenterology 2010; 139: $1444-1447$ 
92 Pohl H, Srivastava A, Bensen SP et al. Incomplete polyp resection during colonoscopy - results of the complete adenoma resection (CARE) study. Gastroenterology 2013; 144: 74-80, e71

93 Khashab M, Eid E, Rusche $M$ et al. Incidence and predictors of "late" recurrences after endoscopic piecemeal resection of large sessile adenomas. Gastrointest Endosc 2009; 70: 344-349

94 Martínez ME, Baron JA, Lieberman DA et al. A pooled analysis of advanced colorectal neoplasia diagnoses after colonoscopic polypectomy. Gastroenterology 2009; 136: 832 - 841

95 Zauber $A G$, Lansdorp-Vogelaar I, Knudsen $A B$ et al. Evaluating test strategies for colorectal cancer screening: a decision analysis for the U.S. Preventive Services Task Force. Ann Intern Med 2008; 149: 659 669

96 Keighley MR. Gastrointestinal cancers in Europe. Aliment Pharmacol Ther 2003; $18: 037-30$

97 Yang DH, Hong SN, Kim YH et al. Korean guidelines for postpolypectomy colonoscopy surveillance. Clinical Endosc 2012; 45: 44-61

98 Bertario L, Russo A, Sala P et al. Predictors of metachronous colorectal neoplasms in sporadic adenoma patients. Int J Cancer 2003; 105: 82 87

99 Laiyemo AO, Murphy G, Albert PS et al. Postpolypectomy colonoscopy surveillance guidelines: predictive accuracy for advanced adenoma at 4 years. Ann Intern Med 2008; 148: 419-426

100 Laiyemo AO, Doubeni C, Brim H et al. Short- and long-term risk of colorectal adenoma recurrence among whites and blacks. Gastrointest Endosc 2013; 77: $447-454$

101 Harewood GC, Sharma VK, de Garmo P. Impact of colonoscopy preparation quality on detection of suspected colonic neoplasia. Gastrointest Endosc 2003; 58: 76 - 79

102 Froehlich F, Wietlisbach V, Gonvers JJ et al. Impact of colonic cleansing on quality and diagnostic yield of colonoscopy: the European Panel of Appropriateness of Gastrointestinal Endoscopy European multicenter study. Gastrointest Endosc 2005; 61: 378-384

103 Rex DK, Bond JH, Winawer $S$ et al. Quality in the technical performance of colonoscopy and the continuous quality improvement process for colonoscopy: recommendations of the U.S. Multi-Society Task Force on Colorectal Cancer. Am J Gastroenterol 2002; 97: 1296-1308

104 van Heijningen EM, Lansdorp-Vogelaar I, Kuipers EJ et al. Features of adenoma and colonoscopy associated with recurrent colorectal neoplasia, based on a large, community-based study. Gastroenterology 2013; 144: 1410 - 1418. Epub 2013 Mar 7

105 Lane JM, Chow E, Young GP et al. Interval fecal immunochemical testing in a colonoscopic surveillance program speeds detection of colorectal neoplasia. Gastroenterology 2010; 139: 1918-1926

106 Bampton PA, Sandford IJ, Cole SR et al. Interval faecal occult blood testing in a colonoscopy based screening programme detects additional pathology. Gut 2005; 54: $803-806$

107 Segnan N, Senore C, Andreoni B et al. Comparing attendance and detection rate of colonoscopy with sigmoidoscopy and FIT for colorectal cancer screening. Gastroenterology 2007; 132: $2304-2312$

108 Lebwohl B, Kastrinos F, Glick M et al. The impact of suboptimal bowel preparation on adenoma miss rates and the factors associated with early repeat colonoscopy. Gastrointest Endosc 2011; 73: 1207-1214
109 Chokshi RV, Hovis CE, Hollander T et al. Prevalence of missed adenomas in patients with inadequate bowel preparation on screening colonoscopy. Gastrointest Endosc 2012; 75: 1197 - 1203

110 Hillyer GC, Basch CH, Lebwohl B et al. Shortened surveillance intervals following suboptimal bowel preparation for colonoscopy: results of a national survey. Int J Colorect Dis 2013; 28: 73 -81

111 Kim ER, Sinn DH, Kim JY et al. Factors associated with adherence to the recommended postpolypectomy surveillance interval. Surg Endosc 2012; 26: 1690 - 1695

112 Toyonaga T, Man-i M, Fujita T et al. Retrospective study of technical aspects and complications of endoscopic submucosal dissection for laterally spreading tumors of the colorectum. Endoscopy 2010; 42: $714-722$

113 Tanaka S, Haruma K, Oka S et al. Clinicopathologic features and endoscopic treatment of superficially spreading colorectal neoplasms larger than $20 \mathrm{~mm}$. Gastrointest Endosc 2001; 54: 62-66

114 Cao Y, Liao C, Tan A et al. Meta-analysis of endoscopic submucosal dissection versus endoscopic mucosal resection for tumors of the gastrointestinal tract. Endoscopy 2009; 41: 751 - 757

115 Moss ABJ, William S, Hourigan $L$ et al. Long term recurrence following wide field endoscopic mucosal resection (WF-EMR) for advanced colonic mucosal neoplasia - results of the Australian Colonic EMR (ACE) multicenter prospective study of 940 patients. Gastrointest Endosc 2012; 75 4S: AB177

116 Park JJ, Cheon JH, Kwon JE et al. Clinical outcomes and factors related to resectability and curability of EMR for early colorectal cancer. Gastrointest Endosc 2011; 74: 1337-1346

117 Repici A, Hassan C, De Paula Pessoa D et al. Efficacy and safety of endoscopic submucosal dissection for colorectal neoplasia: a systematic review. Endoscopy 2012; 44: 137 - 150

118 Moss A, Bourke MJ, Williams SJ et al. Endoscopic mucosal resection outcomes and prediction of submucosal cancer from advanced colonic mucosal neoplasia. Gastroenterology 2011; 140: 1909-1918

119 Noshirwani KC, van Stolk RU, Rybicki LA et al. Adenoma size and number are predictive of adenoma recurrence: implications for surveillance colonoscopy. Gastrointest Endosc 2000; 51: 433-437

120 Bonithon-Kopp C, Piard F, Fenger $C$ et al. Colorectal adenoma characteristics as predictors of recurrence. Dis Colon Rectum 2004; 47 $323-333$

121 Matsuda T, Fujii T, Sano Y et al. Five-year incidence of advanced neoplasia after initial colonoscopy in Japan: a multicenter retrospective cohort study. Jpn J Clin Oncol 2009; 39: 435-442

122 Blumberg D, Opelka FG, Hicks TC et al. Significance of a normal surveillance colonoscopy in patients with a history of adenomatous polyps. Dis Colon Rectum 2000; 43: 1084-1091; discussion 1091-1082

123 Rex DK, Kahi CJ, Levin B et al. Guidelines for colonoscopy surveillance after cancer resection: A consensus update by the American Cancer Society and the US Multi-Society Task Force on Colorectal Cancer. Gastroenterology 2006; 130: 1865-1871

124 Huang $E H$, Whelan $R L$, Gleason NR et al. Increased incidence of colorectal adenomas in follow-up evaluation of patients with newly diagnosed hyperplastic polyps. Surg Endosc 2001; 15: 646-648

Appendix e1 and e2, Table e1 - e8,

online content viewable at: www.thieme-connect.de 